\title{
Evaluasi Kinerja IPAL - IPAL Program SPBM- USRI Tahun Pembangunan 2012 - 2014 di Surabaya
}

\author{
Aulia H. Bhakti dan Welly Herumurti \\ Jurusan Teknik Lingkungan, Fakultas Teknik Sipil dan Perencanaan, Institut Teknologi Sepuluh \\ Nopember (ITS) \\ Jl. Arief Rahman Hakim, Surabaya 60111 Indonesia \\ e-mail:wellyherumurti@enviro.its.ac.id
}

\begin{abstract}
Abstrak-Program SPBM-USRI telah membangun 40 unit fasilitas sanitasi di Surabaya pada Tahun 2012 - 2014 yang meliputi 17 MCK++, 13 MCK Kombinasi, dan 10 IPAL Komunal. Evaluasi dilakukan untuk menentukan kinerja pelaksanaan dan strategi peningkatan kinerja program yang ditinjau dari aspek teknis. Data primer didapatkan dari observasi lapangan, wawancara penanggung jawab, dan pengujian kualitas air limbah. Data sekunder yang digunakan adalah DED dan karakteristik air limbah yang telah diuji BLH. Evaluasi dilakukan dengan metode analisis scoring dan pembobotan serta analisis SWOT. Terdapat 3 unit bangunan MCK++ dan 4 unit bangunan MCK Kombinasi yang terbengkalai. Kinerja pelaksanaan program ditinjau dari aspek teknis adalah buruk dengan nilai evaluasi sebesar $45,1 \%$. Kinerja program tiap jenis fasilitas beserta hasil nilai evaluasinya masing - masing adalah MCK++ berkinerja baik $(54,8 \%)$, MCK Kombinasi buruk (40,9\%), dan IPAL Komunal buruk (34,2\%). Peningkatan kinerja pelaksanaan Program SPBM ditinjau dari aspek teknis adalah melalui perbaikan sarana MCK, perbaikan manhole, peningkatan intensitas pemeliharaan, serta meningkatkan kinerja IPAL dengan cara: menambahkan mikroba, meningkatkan frekuensi pengurasan, membersihkan biofilter, menambahkan filter eksternal, maupun menambahkan kompartemen.
\end{abstract}

Kata Kunci-Aspek Teknis, IPAL, MCK, Sanitasi, Scoring dan Pembobotan, SPBM, USRI, SWOT.

\section{PENDAHULUAN}

$\mathrm{D}$ I Surabaya, sebanyak 13.908 rumah tangga belum memiliki fasilitas buang air besar [1]. Disamping itu, masih banyak dijumpai rumah tangga di Surabaya yang membuang limbahnya langsung ke badan air tanpa diolah terlebih dahulu. Akibatnya, sekitar 50\% pencemaran badan air di Surabaya disebabkan oleh cemaran limbah domestik [2]. Langkah kongkret yang dilakukan pemerintah untuk meningkatkan akses sanitasi di Surabaya adalah melalui program Sanitasi Perkotaan Berbasis Masyarakat (SPBM). Program SPBM merupakan salah satu komponen program Urban Sanitation and Rural Infratruscture (USRI) yang juga diselenggarakan sebagai pendukung program PNPM-Mandiri [3]. Menurut data yang diperoleh dari Dinas Pekerjaan Umum Kota Surabaya, fasilitas - fasilitas sanitasi hasil Program SPBM yang dibangun pada tahun 2012 hingga tahun 2014 di Surabaya terdapat sebanyak 40 unit yang tersebar di 14 kecamatan. Fasilitas tersebut terdiri dari 3 jenis dengan jumlah masing - masing adalah 17 MCK++, 13 Kombinasi MCK dengan perpipaan, dan 10 IPAL Komunal. IPAL dioperasikan untuk mengolah air limbah domestik sehingga dapat menurunkan kadar pencemar organik maupun non-organik sehingga dapat mengurangi pencemaran lingkungan akibat limbah domestik [4].

Program SPBM memiliki beberapa prinsip penyelenggaraan, antara lain: dapat diterima, transparan, dapat dipertanggungjawabkan, berkelanjutan, memiliki kerangka jangka menengah, dan sederhana [3]. Namun dalam praktiknya, kondisi di lapangan seringkali berbeda dengan prinsip penyelenggaraan tersebut. Beberapa fasilitas sanitasi yang terbangun diduga terbengkalai atau tidak berjalan maksimal karena kesalahan pembangunan, pengoperasian, maupun pemeliharaan. Keadaan ini menjadi kajian yang menarik mengingat dana yang digunakan untuk Program SPBM tidaklah sedikit, yakni maksimal Rp 350.000 .000 tiap fasilitas sanitasi. Disamping itu, target RPJMN RI 2015 2019 mengenai sanitasi, yakni sebanyak 100\% masyarakat Indonesia telah memiliki akses dasar sanitasi, mendesak untuk segera dipenuhi [5]. Target tersebut didasarkan pada Sustainable Development Goals yang dirumuskan oleh PBB mengenai Universal Access, yakni semua elemen masyarakat harus dapat memiliki akses sanitasi dan air bersih yang mudah dan murah [6].

Evaluasi dilakukan dengan memperhatikan aspek teknis yang mengkaji kesesuaian bangunan berdasarkan kriteria desain, kinerja IPAL berdasarkan baku mutu air limbah, serta pengoperasian dan pemeliharaan yang dilakukan. Kinerja pelaksanaan program ditentukan dengan metode analisis scoring dan pembobotan. Dari kinerja yang telah diketahui, ditentukan strategi peningkatan pelaksanaan program dengan metode analisis Strength, Weakness, Opportunity, Threat (SWOT). Analisis SWOT merupakan perangkat umum yang didesain dan digunakan sebagai langkah awal dalam proses pembuatan keputusan dan sebagai perencanaan strategis dalam berbagai terapan masalah yang dihadapi [7]. Dengan demikian, IPAL - IPAL Komunal Program SPBM - USRI diharapkan dapat berjalan lebih optimal dalam mengolah limbah domestik di Surabaya. 


\section{METODE EVALUASI}

\section{A. Pengumpulan Data Survai dan Pemilihan Sampel}

Survai dilakukan terhadap 40 unit sanitasi yang tersebar di surabaya dengan metode observasi lapangan dan wawancara terstruktur terhadap penanggung jawab. Observasi adalah metode untuk menyajikan gambaran realistik perilaku atau kejadian, untuk menjawab pertanyaan, untuk membantu mengerti perilaku manusia, dan untuk evaluasi yaitu melakukan pengukuran terhadap aspek tertentu melakukan umpan balik terhadap pengukuran tersebut [8]. Observasi Lapangan dilakukan dengan mengecek kondisi fisik fasilitas sanitasi. Wawancara [9] merupakan alat re-checking atau pembuktian terhadap informasi atau keterangan yang diperoleh sebelumnya. Wawancara terstruktur dilakukan pada penanggung jawab fasilitas sanitasi mengenai pemeliharaan dan pengoperasian fasilitas sanitasi.

Hasil dari survai pendahuluan digunakan sebagai acuan bagi penentuan sampel untuk dilakukan survai lanjutan. Metode pemilihan sampel fasilitas sanitasi adalah dengan metode stratified non proportional sampling. Metode stratified non proportional sampling merupakan salah satu metode stratified random sampling, yakni metode penarikan sampel yang dilakukan dengan cara membagi populasi menjadi populasi yang lebih kecil (stratum), pembentukan stratum harus sedemikian rupa sehingga setiap sratum homogen berdasarkan suatu atau beberapa kriteria tertentu, kemudian dari setiap stratum diambil sampel secara acak. Pada metode stratified non proportional sampling, hasil sampel yang dipilih secara acak berjumlah atau berkapasitas sama tiap stratum [10]. Strata sampel pada studi ini adalah Jenis Fasilitas. Dengan demikian, jumlah strata adalah sebanyak 3 strata, yakni kelompok fasilitas MCK++, MCK dengan perpipaan, dan IPAL Komunal. Jumlah sampel yang dipilih secara acak pada studi ini adalah sebanyak 2 sampel tiap stratum. Sehingga, total jumlah sampel fasilitas sanitasi yang akan dilakukan survai lanjutan adalah sebanyak 6 unit. Pada evaluasi ini dipilih 1 unit tambahan MCK Kombinasi sehingga jumlah unit yang dilakukan evaluasi lanjutan sebanyak 7 unit. Pemilihan fasilitas - fasilitas sanitasi didasarkan pada pertimbangan variasi tahun pembangunan $(2012,2013$, dan 2014) dan jenis fasilitas sanitasi.

\section{B. Survai Lanjutan}

Survai lanjutan dilakukan terhadap 7 sampel IPAL representatif yang telah dipilih. Data - data sekunder dan primer yang diambil adalah sebagai berikut:

1. Data Sekunder

Data sekunder yang dibutuhkan adalah dokumen Rencana Kegiatan Masyarakat (RKM), DED Fasilitas Sanitasi, serta kualitas efluen IPAL. Data - data tersebut didapatkan dari POKJA ULP SATKER PPLP Jawa Timur dan Badan Lingkungan Hidup (BLH).

\section{Data Primer}

Data primer yang diperlukan adalah kualitas sampel influen dan efluen IPAL yang belum diuji oleh BLH. Data tersebut diperoleh dari sampling dan pengujian laboratorium.
Pengambilan sampel efluen IPAL dilakukan dengan cara grab sampling. Grab Sampling yang dilakukan mengacu pada SNI 6989-59-2008 mengenai metode pengambilan contoh air limbah. Kualitas sampel air limbah diuji sesuai parameter pada baku mutu air limbah PerGub Jatim No. 72 Tahun 2013, yakni BOD, COD, TSS, suhu, dan pH [11].

\section{Analisis Scoring dan Pembobotan}

Analisis scoring dan pembobotan dilakukan untuk menentukan kinerja pelaksanaan program. Analisis scoring dilakukan berdasarkan hasil survai dan mengacu pada beberapa parameter indikator internal dan eksternal.

Parameter indikator internal merupakan parameter yang ditinjau dari kondisi internal bangunan fasilitas yang telah terbangun. Parameter indikator internal diantaranya adalah:

1. Ketersediaan sumber air dan sistem plambing serta kondisi fisik MCK

2. Kesesuaian jumlah pengguna dengan jumlah sarana MCK terbangun berdasarkan SNI 03-2399-2002 [12]

3. Bahan dan kondisi manhole IPAL

4. Kinerja IPAL dengan analisis kesesuaian kualitas efluen IPAL baku mutu [11], yakni COD maksimal $50 \mathrm{mg} / \mathrm{L}$, BOD maksimal $30 \mathrm{mg} / \mathrm{L}$, dan TSS maksimal $50 \mathrm{mg} / \mathrm{L}$.

5. Kesesuaian bangunan IPAL dengan kriteria desain [13] ditinjau dari 3 parameter dengan masing - masing kriteria desain, yakni HRT minimal 8 jam, Vup maksimal $2 \mathrm{~m} / \mathrm{s}$, dan OLR maksimal $3 \mathrm{~kg} / \mathrm{m} 3$.hari

Parameter indikator internal merupakan parameter yang ditinjau dari segi kondisi eksternal bangunan, yakni lingkungan pada lokasi fasilitas serta pengoperasian dan pemeliharaan fasilitas. Parameter indikator internal diantaranya adalah:

1. Kondisi genangan/banjir (frekuensi, durasi, dan tinggi genangan)

2. Pengoperasian (keberadaan SOP dan operator IPAL)

3. Pemeliharaan bangunan MCK

4. Pemeliharaan bak kontrol/manhole bangunan IPAL

5. Pemeliharaan bak kontrol/manhole jaringan

6. Pemeriksaan kualitas efluen IPAL

Pembobotan dilakukan oleh para ahli, yakni ketua KPP dan dosen. Hasil nilai dari analisis scoring dan pembobotan digunakan untuk menentukan kategori kinerja/performa pelaksanaan program berdasarkan kategori nilai pada Tabel 1 .

Tabel 1.

Kategori Kinerja/Performa Pelaksanaan Program

\begin{tabular}{ccc}
\hline \hline $\begin{array}{c}\text { Kategori } \\
\text { Kinerja/Performa }\end{array}$ & Nilai & Persen Nilai \\
\hline Sangat Baik & $4,01-5$ & $75-100 \%$ \\
Baik & $3,01-4$ & $50-74,9 \%$ \\
Buruk & $1,01-2$ & $25-49,9 \%$ \\
Sangat Buruk & $0-1$ & $0-24,9 \%$ \\
\hline \hline
\end{tabular}

\section{Analisis SWOT}

Analisis SWOT membandingkan antara faktor eksternal (opportunity dan threat) dengan faktor internal (strength dan weakness). Analisis SWOT ditentukan dengan pengeplotan hasil nilai indikator tiap sub aspek terhadap kuadran SWOT [14]. Hasil pengeplotan kuadran SWOT tersebut digunakan untuk menentukan strategi peningkatan performa program 
yang paling sesuai. Analisis SWOT dilakukan berdasarkan aspek teknis dan aspek sosial pada seluruh unit secara umum dan pada tiap jenis fasilitas sanitasi.

\section{HASIL DAN DISKUSI}

\section{A. Hasil Survai}

Berdasarkan observasi lapangan yang dilakukan terhadap 40 unit fasilitas sanitasi, terdapat 7 unit (18\%) fasilitas yang terbengkalai, 7 unit $(18 \%)$ fasilitas yang kurang dijalankan, dan 24 unit (64\%) fasilitas yang sedang dijalankan.

Fasilitas terbengkalai merupakan fasilitas yang tidak digunakan atau tidak layak digunakan sehingga menjadi monumen. Fasilitas - fasilitas tersebut terdiri dari 3 unit MCK++ dan 4 unit MCK Kombinasi. Bangunan MCK++ yang terbengkalai terletak di Jl Kalimas Barat, Jl Pantai Kenjeran 22, dan Jl Ikan Dorang. MCK Kombinasi yang terbengkalai terletak di Jl Halimun, Jl Kebalen Kulon, J1 Pesapen Kali, dan Jl Penambangan Perak.

Hasil survai terhadap 30 unit MCK++ dan MCK Kombinasi mengenai kondisi sumber air MCK menunjukkan sebanyak 13 unit (42\%) menggunakan PDAM, 11 unit (37\%) menggunakan sumur, dan sisanya 6 unit (23\%) tidak memiliki sumber air. Sumur yang digunakan adalah sumur bor dan sumur gali. MCK yang tidak memiliki sumber air semuanya merupakan MCK terbengkalai. Tidak adanya sumber air disebabkan tidak dipasang PDAM maupun karena air sumur yang asin. Pada musim kemarau, beberapa MCK mengalami kesulitan air karena sumur surut. Meskipun beberapa lokasi mengalami kesulitan air, penggunaan air pada MCK dapat dikatakan cukup baik karena sebanyak $42 \%$ telah menggunakan PDAM.

Sistem plambing yang telah terpasang sebanyak 27 unit dan 3 unit (11\%) yang tidak dibangun sistem plambing dengan lengkap sehingga bangunan terbengkalai. Sebanyak 23 unit (74\%) memiliki sistem plambing yang berfungsi baik sedangkan sisanya 4 unit (15\%) tidak berfungsi karena bangunan terbengkalai. Diagram persentase kondisi sumber air dan sistem plambing dapat dilihat pada Gambar 1.

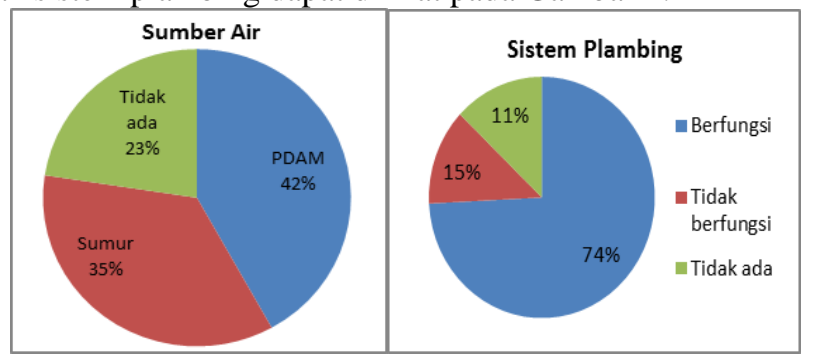

Gambar 1. Kondisi Sumber Air dan Sistem Plambing Bangunan MCK Program SPBM-USRI

Ditinjau dari kondisi kebersihan dari 30 unit MCK, terdapat 64\% (19 unit) bangunan yang bersih terawat, 13\% (4 unit) yang kurang terawat, dan $23 \%$ sisanya (7 unit) merupakan MCK terbengkalai sehingga tidak terawat.

Sarana sanitasi yang terbangun juga seharusnya memenuhi kapasitas pelayanan yang telah diatur pada SNI 03-2399-2002. Kondisi di lapangan menunjukkan hanya 7 unit dari 30 unit MCK dengan kapasitas sarana bilik mandi dan kakus yang telah memenuhi SNI. Banyaknya kapasitas sarana yang kurang sesuai disebabkan pada beberapa MCK jumlah sarana yang terbangun melebihi jumlah pemanfaat dan pada MCK lainnya jumlah pemanfaat melebihi kapasitas sarana yang ada. Kurangnya jumlah pemanfaat disebabkan berbagai hal, diantaranya kerusakan sarana, peningkatan jumlah warga yang telah memiliki toilet pribadi, serta masalah sosial internal warga terhadap pihak - pihak pengurus MCK. MCK umumnya dibangun pada lahan yang dulunya MCK lama. Pada MCK di Jl Sukolilo Sukorejo, pembangunan yang memakan waktu rata - rata 1 tahun dirasa terlalu lama sehingga warga telah membangun toilet pribadi sebelum MCK terbangun.

Di Surabaya, IPAL yang dibangun Program SPBM umumnya berjenis Anaerobic Baffled Reactor (ABR) dan kombinasi ABR dengan Anaerobic Filter (AF). Ditinjau dari kondisi manhole dari 40 IPAL, terdapat 6 unit yang memiliki manhole berbahan besi atau plastik sehingga mudah dibuka, 10 unit tidak memiliki manhole, dan sisanya 24 unit memiliki manhole berbahan beton. Jumlah IPAL dengan manhole yang mudah/dapat dibuka sebanyak 12 unit. IPAL Komunal umumnya dibangun di bawah jalan, sehingga banyak IPAL yang manholenya ditutup dengan paving. Manhole yang sulit dibuka juga terjadi karena telah rapat dengan jalan akibat beban kendaraan yang lewat.

Terdapat 7 IPAL yang dilakukan evaluasi lanjutan, dengan rincian lokasi pada Tabel 2.

Tabel 2.

Jenis Fasilitas, Lokasi, dan Jenis IPAL Evaluasi Lanjutan

\begin{tabular}{|c|c|c|c|}
\hline No. & $\begin{array}{c}\text { Jenis } \\
\text { Fasilitas }\end{array}$ & Lokasi IPAL & Jenis IPAL \\
\hline IPAL A & $\mathrm{MCK}++$ & J1 Kalibutuh Timur Gang 3 & AFBR batu \\
\hline IPAL B & $\mathrm{MCK}++$ & J1 Sukorejo No. 9 RT 5 RW 2 & $\begin{array}{c}\text { AFBR } \\
\text { plastik }\end{array}$ \\
\hline IPAL C & MCK K & Jl. Surabayan IV RT 7 RW 2 & AFBR \\
\hline IPAL D & MCK K & J1. Dinoyo Magersari Tambang & AFBR \\
\hline IPAL E & MCK K & Jl Rungkut tengah gang sawah & $\begin{array}{l}\text { AFBR } \\
\text { bioball }\end{array}$ \\
\hline IPAL F & IPAL & J1. Penanggungan RT 4 / RW 5 & $\mathrm{ABR}$ \\
\hline IPAL G & IPAL & J1. Bendul Merisi Jaya RT2 / RW12 & AFBR batu \\
\hline
\end{tabular}

Kualitas influen dan efluen IPAL dapat dilihat pada Tabel 3. Ditinjau dari kinerja IPAL dalam mengolah air limbah, hanya terdapat 1 IPAL yang menghasilkan efluen sesuai baku mutu PerGub Jatim No. 72 Tahun 2013, yakni MCK di Jl Sukorejo (IPAL B).

Tabel 3.

Kualitas Influen dan Efluen IPAL

\begin{tabular}{|c|c|c|c|c|c|c|}
\hline \multirow{2}{*}{ No. } & \multicolumn{2}{|c|}{ TSS (mg/L) } & \multicolumn{2}{|c|}{ BODs (mg/L) } & \multicolumn{2}{|c|}{ COD $(\mathrm{mg} / \mathrm{L})$} \\
\hline & influen & efluen & influen & efluen & influen & efluen \\
\hline IPAL A & - & - & - & 20,16 & - & 198,48 \\
\hline IPAL B & 214,00 & 37,0 & 306,00 & 17,43 & 488,0 & 20,32 \\
\hline IPAL C & 120,00 & 86,0 & 101,50 & 92,40 & 263,7 & 241,30 \\
\hline IPAL D & 160,00 & 150,0 & 105,00 & 60,00 & 167,0 & 94,00 \\
\hline IPAL E & - & 210,0 & - & 146,00 & - & 235,00 \\
\hline IPAL F & - & 18,5 & - & 90,38 & - & 257,42 \\
\hline IPAL G & - & 51,0 & - & 80,62 & - & 151,99 \\
\hline
\end{tabular}


Meskipun banyak IPAL tidak menghasilkan efluen sesuai yang diinginkan, evaluasi desain IPAL pada 6 IPAL menunjukkan hasil terdapat 3 IPAL yang tidak memenuhi kriteria desain dari parameter HRT saja. Hasil perhitungan sesuai parameter kriteria desain selengkapnya dapat dilihat pada Tabel 4.

Tabel 4.

Hasil Perhitungan HRT, OLR, dan Vup

\begin{tabular}{|c|c|c|c|c|c|c|}
\hline $\begin{array}{l}\text { No. } \\
\text { IPAL }\end{array}$ & $\begin{array}{l}\text { HRT } \\
\text { (jam) }\end{array}$ & $\mathrm{KD}>8$ & $\begin{array}{c}\text { OLR } \\
(\mathrm{kg} \\
\text { COD/ } \\
\text { m3/hari) } \\
\end{array}$ & $\mathrm{KD}<3$ & $\begin{array}{l}\text { Vup } \\
\text { (m/ } \\
\text { jam) }\end{array}$ & $\mathrm{KD}<2$ \\
\hline A & 22,1 & Memenuhi & 0,28 & Memenuhi & 0,34 & Memenuhi \\
\hline B & 253,7 & Memenuhi & 0,05 & Memenuhi & 0,07 & Memenuhi \\
\hline $\mathrm{C}$ & 5,4 & $\begin{array}{c}\text { Tidak } \\
\text { memenuhi }\end{array}$ & 1,17 & Memenuhi & 1,11 & Memenuhi \\
\hline D & 5,3 & $\begin{array}{c}\text { Tidak } \\
\text { memenuhi }\end{array}$ & 0,76 & Memenuhi & 1,14 & Memenuhi \\
\hline E & 13,0 & Memenuhi & 0,90 & Memenuhi & 0,46 & Memenuhi \\
\hline $\mathrm{G}$ & 5,6 & $\begin{array}{c}\text { Tidak } \\
\text { memenuhi }\end{array}$ & 1,11 & Memenuhi & 1,67 & Memenuhi \\
\hline
\end{tabular}

Ditinjau dari segi genangan/banjir, sebanyak 19 unit telah dibangun pada lokasi bebas genangan namun sebanyak 7 unit berada pada daerah banjir setiap hujan lebat. Tinggi genangan banjir yang banyak terjadi adalah setinggi $21-60 \mathrm{~cm}$.

Evaluasi dari parameter pengoperasian dan pemeliharaan fasilitas dilakukan pada 33 unit fasilitas yang dijalankan atau tidak terbengkalai serta ditinjau dari keberadaan Standard Operation Procedure (SOP) dan operator IPAL. Sebanyak 14 unit telah memiliki SOP tertulis, 6 unit memiliki SOP tidak tertulis, dan sisanya 13 unit tidak memiliki SOP. Fasilitas yang memiliki operator IPAL khusus hanya terdapat 12 unit (36\%). Diagram persentase keberadaan SOP dan operator IPAL dapat dilihat pada Gambar 2.

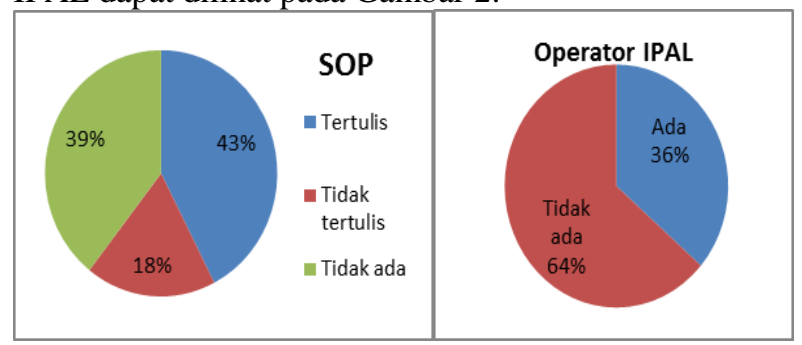

Gambar 2. Keberadaan SOP dan Operator IPAL

Dari 23 unit MCK yang dijalankan, pemeliharaan bangunan MCK dinilai telah baik karena mayoritas pemeliharaan bangunan, yakni 15 unit (65\%), dilakukan oleh Penanggung jawab. Frekuensi pembersihan pun telah cukup sesuai dengan peraturan, yakni pada 8 unit (35\%) bangunan MCK, dibersihkan setiap hari. Sebagian besar pembersihan dilakukan 2 -3 kali seminggu pada 11 unit MCK (48\%).

Pemeliharaan harus dilakukan pada bangunan IPAL dan jaringan. Pemeliharaan bangunan IPAL dilakukan dengan memantau dan membuang kotoran tepat di bawah manhole atau bak kontrol bangunan IPAL selama 6 bulan sekali. Selain itu, pengujian kualitas air limbah perlu dilakukan 1 kali per 6 bulan pada inlet dan outlet IPAL [3]. Dari 33 IPAL fasilitas yang dijalankan, terdapat 13 unit IPAL yang dipantau, namun hanya 8 unit diantaranya yang dipantau sesuai prosedur, yakni 6 bulan sekali. Dari 13 unit IPAL yang dipantau, hanya terdapat 5 unit yang pernah dibersihkan kotorannya. Pengujian kualitas influen dan efluen air limbah telah dilakukan oleh pihan Badan Lingkungan Hidup Surabaya terhadap 15 unit IPAL Program SPBM, namun hanya 7 diantaranya dilakukan pada durasi pengujian sesuai prosedur, yakni 6 bulan sekali. Pengujian kualitas air limbah perlu dilakukan pada seluruh unit yang dijalankan.

Pemeliharaan jaringan sambungan IPAL dilakukan dengan memantau manhole atau bak kontol pada jaringan perpipaan yang dilanjutkan dengan pembuangan kotoran [3]. Pemantauan pada manhole umumnya dilakukan oleh operator sedangkan pemantauan bak kontrol dilakukan pada pemanfaat tiap Sambungan Rumah (SR) selama kurang lebih 2 minggu sekali. Dari 19 unit MCK Kombinasi dan IPAL komunal, terdapat 9 unit yang melakukan pemeliharaan jaringan dimana hanya 4 unit diantaranya yang melakukan pemeliharaan jaringan sesuai durasi yang disarankan. Kesembilan IPAL tersebut melakukan perawatan jaringan dengan membuang kotoran pada jaringan, namun hanya 5 diantaranya yang melakukan pemeliharaan dengan penggelontoran air.

\section{B. Kinerja Program}

Bobot untuk parameter indikator internal dan eksternal masing - masing adalah $60 \%$ dan $40 \%$. Kinerja pelaksanaan program secara keseluruhan ditinjau dari aspek teknis adalah buruk dengan nilai evaluasi $45,1 \%$. Kinerja program tiap jenis fasilitas beserta hasil nilai evaluasinya masing - masing adalah MCK++ berkinerja baik (54,8\%), MCK Kombinasi buruk (40,9\%), dan IPAL Komunal buruk (34,2\%).

\section{Strategi Peningkatan Program}

Analisis SWOT dari faktor internal menunjukkan faktor opportunity bernilai 1,85 lebih kuat dari threat yang bernilai 1,32. Dari faktor eksternal, weakness bernilai 1,87 lebih kuat dari strength yang bernilai 1,81. Kuadran SWOT menunjukkan program terletak pada kuadran III (weaknessopportunity) sehingga strategi yag dapat dirumuskan adalah menggunakan strategi turn around (Gambar 3). Strategi turn around (weakness - opportunity), yakni dengan memaksimalkan peluang atau opportunity yang ada dengan cara meminimalkan kelemahan atau weakness [14].

\section{Gambar 3. Kuadran SWOT}

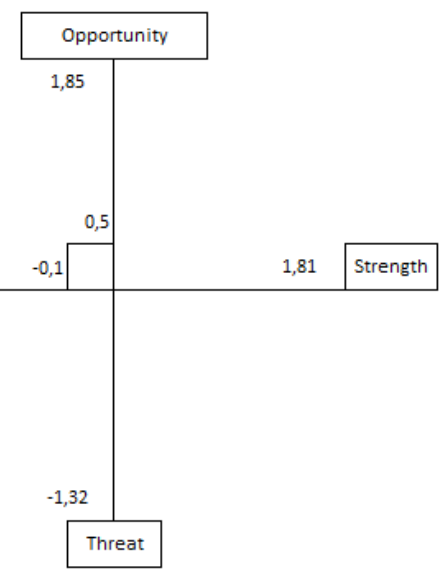

Penentuan strategi pada aspek teknis dirumuskan sebagai berikut: 
1. Memperbaiki sarana mandi, cuci, dan kakus baik dan meningkatkan pemeliharaan MCK dengan melakukan pembersihan maksimal 2 hari sekali

2. Membuat manhole pada IPAL atau jaringan yang tidak memiliki manhole, mengganti manhole berbahan beton menjadi besi yang lebih mudah dibuka, dan tidak menutup manhole dengan paving padat.

3. Meningkatkan durasi pemeliharaan IPAL oleh operator sesuai yang disarankan, yakni untuk bangunan IPAL selama 6 bulan sekali dan jaringan selama 2 minggu sekali. Pemeliharaan dilakukan dengan pemantauan rutin dan membersihkan kotoran. Pada jaringan, ditambahkan penggelontoran bersama dari bak kontrol oleh warga.

4. Meningkatkan kinerja IPAL dengan menambahkan mikroba dan membersihkan biofilter. Penambahan mikroorganisme dimaksudkan agar tercipta kondisi F/M yang rendah. Nilai F/M rendah menyebabkan sistem kekuragan makanan sehingga menghasilkan degradasi limbah yang lebih baik [15]. Mikroorganisme yang ditambahkan dapat berupa EM4, M-Bio, maupun biostarter alami buatan sendiri dari nanas atau kotoran ternak. Penambahan biostarter M-Bio sebanyak $5 \mathrm{~mL} / \mathrm{L}$ pada IPAL Asrama Mahasisa UI dapat meningkatkan efisiensi penurunan COD sebanyak $83.06 \%$, PO43- $86,76 \%$, NO3$65,14 \%$, NO2- $73,40 \%$, TSS $71,15 \%$, serta E coli $83,78 \%$ [16].

5. Pada IPAL dengan efluen yang mengandung TSS cukup tinggi, perlu dibuat unit filter eksternal sederhana maupun meningkatkan durasi pengurasan.

6. Pada IPAL yang memiliki sisa lahan, perlu ditambahkan kompartemen untuk meningkatkan waktu kontak (HRT) sehingga dapat meningkatkan kinerja IPAL. IPAL yang memiliki sisa lahan berlokasi di Jl Rungkut Tengah dan J1 Bendul Merisi Jaya. Untuk mendapatkan efisiensi penyisihan sehingga kualitas efluen memenuhi baku mutu, pada IPAL di Jl Rungkut Tengah dapat ditambahkan 1 unit kompartemen bak pengendap berdimensi panjang $2 \mathrm{~m}$, lebar $1,5 \mathrm{~m}$, dan tinggi air $2 \mathrm{~m}$ serta AF bersekat dengan dimensi yang sama dengan bak pengendap sebanyak 5 kompartemen. Pada IPAL di Jl Bendul Merisi, dapat ditambahkan IPAL berseri jenis kombinasi ABR-AF dengan dimensi tiap kompartemen panjang 1,5 m, lebar 1 $\mathrm{m}$, dan tinggi air 2,35 m. Kompartemen ABR berjumlah 6 buah dan AF berjumlah 1 buah.

\section{KESIMPULAN/RINGKASAN}

Kesimpulan pada Evaluasi Pelaksanaan Program SPBM USRI Tahun Pembangunan 2012 - 2014 di Surabaya adalah sebagai berikut:

1. Dari 40 unit fasilitas sanitasi yang terbangun, terdapat 3 unit bangunan $\mathrm{MCK}++$ dan 4 unit bangunan MCK Kombinasi yang terbengkalai. Kinerja pelaksanaan program secara keseluruhan ditinjau dari aspek teknis adalah buruk dengan nilai evaluasi $45,1 \%$. Kinerja program tiap jenis fasilitas beserta hasil nilai evaluasinya masing masing adalah MCK++ berkinerja baik $(54,8 \%)$, MCK Kombinasi buruk $(40,9 \%)$, dan IPAL Komunal buruk $(34,2 \%)$.
2. Peningkatan kinerja pelaksanaan Program SPBM ditinjau dari aspek teknis adalah melalui perbaikan sarana MCK dan manhole serta meningkatkan kinerja IPAL. Peningkatan kinerja IPAL dapat dilakukan dengan menambahkan mikroba, membersihkan biofilter, menambahkan filter eksernal, meningkatkan frekuensi pengurasan, maupun menambahkan kompartemen pada lokasi IPAL dengan lahan cukup.

\section{UCAPAN TERIMA KASIH}

Ucapan terima kasih disampaikan kepada Badan Lingkungan Hidup Kota Surabaya, Direktorat Cipta Karya Departemen Pekerjaan Umum Kota Surabaya, dan Kepada Kelompok Pemanfaat dan Pemerhati Sanitasi Kota Surabaya yang telah membantu selama pengerjaan Tugas Akhir. Ucapan terimakasih disampaikan juga kepada Departemen Direktorat Pendidikan Tinggi, Departemen Pendidikan dan Kebudayaan Republik Indonesia yang telah memberikan dukungan finansial melalui Beasiswa PPA tahun 2014-2016.

\section{DAFTAR PUSTAKA}

[1] Badan Lingkungan Hidup Kota Surabaya, "Status Lingkungan Hidup Daerah Kota Surabaya 2013, ”. BLH Surabaya (2014).

[2] JPNN. (25 Desember 2015). Limbah Domestik Dominasi Pencemaran Kali Kota Surabaya [online]. Diakses pada: http://www.jpnn.com.

[3] Kementerian Pekerjaan Umum Dirjend Cipta Karya, Pedoman Pelaksanaan Program SPBM. Jakarta: PNPM Mandiri (2011).

[4] P. Soewondo. dan A. Yulianto, "The Effect of Aeration Mode on Submerged Anaerobic Bio Filter Reactor for Grey Water Treatment" dalam Journal of Applied Science and Environmental Sanitation. Volume 3 (2008) Number 3 : 169-175.

[5] Kementerian Perencanaan Pembangunan Nasional, "Rencana Pembangunan Jangka Menengah Republik Indonesia" (2014).

[6] United Nation (25 Desember 2015). Sustainable Development Goals [online]. Diakses pada: http://www.unitednations.org.

[7] K. M. Batrol dan Martin, Management. New York: McGraw Hill (1991).

[8] H.M. Bungin, Penelitian Kualitatif: Komunikasi, Ekonomi, Kebijakan Publik, dan Ilmu social. Jakarta: Kencana Prenama Media Group (2007).

[9] R. Afriani, "Metode Riset Kualitatif". Artikel Penalaran Lembaga Penelitian Mahasiswa. Universitas Negeri Makasar (2009).

[10] Nurhayati, "Studi Perbandingan Metode Sampling Antara Simple Random Sampling dengan Stratified Random Sampling" dalam Jurnal Basis Data ICT Research Center UNAS Vol.3 (2008) No. 1.

[11] Baku Mutu Air Limbah Domestik, Peraturan Gubernur Jawa Timur No. 72 Tahun 2013.

[12] Tata Cara Perencanaan Bangunan MCK Umum. SNI 03-2399-2002. BSNI.

[13] L. Sasse, DEWATS: Decentralised Wastewater Treatment in Developing Countries. Delhi: BORDA (1998).

[14] F. Rangkuti. Analisis SWOT Teknik Membedah Kasus Bisnis. Jakarta: PT. Gramedia (2000).

[15] R.A. Conwey dan R. D. Ross. Handbook on Industrial Waste Disposal. New York: Van Nostrand Reinhold Co (1980).

[16] D. D. Suryono, "Pengaruh bahan starter terhadap efektivitas pengolahan limbah domestik (Studi kasus pada limbah tangki septik Asrama Mahasiswa Universitas Indonesia, Depok)". Tesis. Pascasarjana Ilmu Lingkungan Universitas Indonesia (2001). 